\title{
Optimization Transmission Efficiency with Driver Intention for Automotive Continuously Variable Transmission under Slip Mode
}

\author{
Ling Han ${ }^{1,2^{*}}$, Hui Zhang ${ }^{2}$, Ruoyu Fang ${ }^{2}$ and Hongxiang Liu ${ }^{2}$
}

\begin{abstract}
This study proposes and experimentally validates an optimal integrated system to control the automotive continuously variable transmission (CVT) by Model Predictive Control (MPC) to achieve its expected transmission efficiency range. The control system framework consists of top and bottom layers. In the top layer, a driving intention recognition system is designed on the basis of fuzzy control strategy to determine the relationship between the driver intention and CVT target ratio at the corresponding time. In the bottom layer, a new slip state dynamic equation is obtained considering slip characteristics and its related constraints, and a clamping force bench is established. Innovatively, a joint controller based on model predictive control (MPC) is designed taking internal combustion engine torque and slip between the metal belt and pulley as optimization dual targets. A cycle is attained by solving the optimization target to achieve optimum engine torque and the input slip in real-time. Moreover, the new controller provides good robustness. Finally, performance is tested by actual CVT vehicles. Results show that compared with traditional control, the proposed control improves vehicle transmission efficiency by approximately $9.12 \%-9.35 \%$ with high accuracy.
\end{abstract}

Keywords: V-belt continuously variable transmission, Model predictive control, Drive intention, Slip mode, Transmission efficiency

\section{Introduction}

Over the past decade, improving transmission efficiency and optimizing power matching have become the main development trend of automatic transmission technology worldwide [1]. In this context, the continuously variable transmission (CVT) offers three benefits over other transmission vehicles [2, 3]. First, high efficiency leads to the best fuel economy curve by reducing transmission loss. Second, small transmission reduces the vehicle weight. Third, zero gear ratio gap can change the speed

\footnotetext{
*Correspondence: hanling@ccut.edu.cn

${ }^{1}$ School of Mechanical and Aerospace Engineering, Jilin University,

Changchun 130025, China

Full list of author information is available at the end of the article
}

ratio continuously at a certain range [4]. Meanwhile, the fuel efficiency of CVT vehicle can increase by $10 \%-15 \%$ and harmful emission substances in automobile exhaust decreases by at least 10\% [5]. Therefore, CVT is an ideal vehicle transmission equipment, which has received much attention and widely used in traditional and hybrid cars [6]. As such, in 2015, automobile companies such as Honda, Toyota, Ford and Volkswagen announced new technology roadmaps that takes CVT technology as the core development direction in the next 15 years. In 2019, CVT consolidated total sales have increased worldwide from 1.78 million in 2015 to 2.0 million in 2019. In the next 20 years, over 2.6 million vehicles are expected to be equipped with CVT after improvements on existing technology, as shown in Figure 1 [7]. However, at present, 


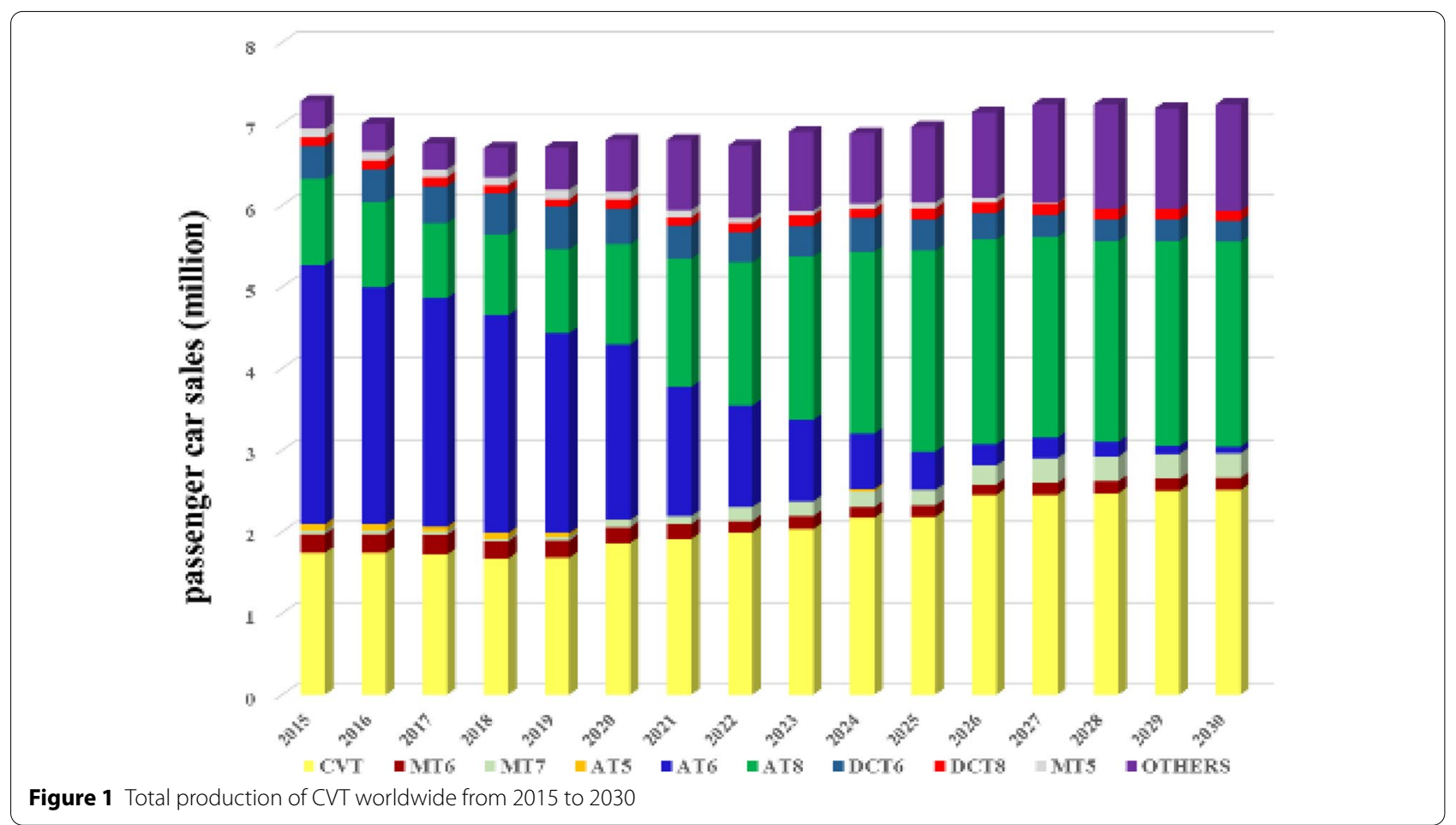

the fuel economy of a vehicle metal belt CVT cannot reach the expected transmission efficiency range of $75 \%-$ 90\%. Several CVT advantages are offset by the required additional hydraulic power consumption of the clamping force acting on the pulleys, which is the root cause of the low efficiency [8]. For many years, the clamping force control strategy typically adopts the safety factor method, and the system is multiplied by a constant factor $\beta$ to satisfy CVT operation under any working conditions. However, while driving, this fixed control range cannot meet real-time road conditions and increases the wear between friction pairs [9].

"Slip mode" means that in order to ensure the reliable operation of the CVT, the clamping force can have a certain margin. Excessive clamping force reduces the efficiency of the hydraulic system and increases the friction loss of the metal belt. Slip control is a new clamping force control method, adopted in the new generation of CVT to allow relative sliding between the belt and the pulleys. A certain degree of slip does not damage the metal belt and increases the friction factor, effectively reduces the clamping force, improves the transmission efficiency, and extends the service life of the CVT (Figure 2) [10]. Thus, CVT not only tends to cause power loss in the metal belt but also (enlarged for clarity) severely affects the driving safety and vehicle service life. Determining the appropriate slip target is necessary, otherwise, the excessive slip rate can cause abrupt changes in the friction factor,

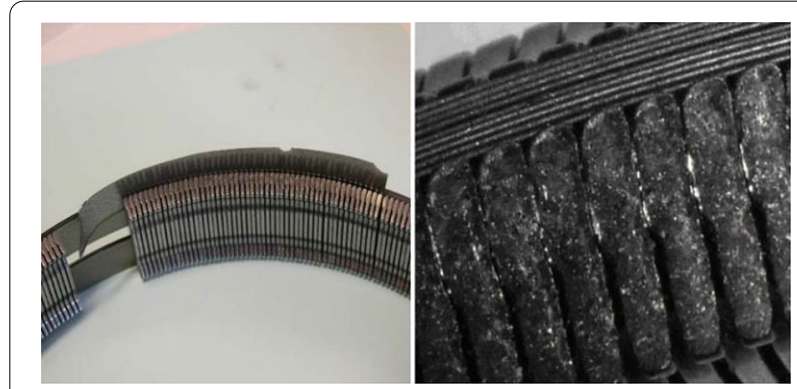

Figure 2 Failure of metal belt and metal sheet

increase the metal sheet wear, and even cause pulley slip failure. Therefore, controlling the slip rate of the metal belt in an ideal area is the key to improve the efficiency of CVT vehicles.

For these reasons, recent research on improving automobile fuel economy widely vary [11]. Liu introduced a multi-range hydro-mechanical transmission to extend the gear ratio [12]. The torque limit under fixed clamping force is analysed through theoretical model and experiment [13], then the characteristics of the slip rate are studied. Controlling the slip rate within an appropriate range is expected to improve the transmission efficiency of the metal belt, but only from an engineering perspective [14]. Lei et al. [15] conducted a CVT transmission efficiency model base on bench test in which gasoline 
with low fuel consumption by measured, however, they ignored the influence of slip. The friction coefficient is expressed as a function of the ratio of the moving arc to the wrap angle of the pulley. Hiroyuki emphatically studied the slip boundary under input torque fluctuation [16]. The transmission loss caused by slip is also examined [17, 18] as applications of slip characteristics, but no study has delved into the theory of slip control. Therefore, this study develops a nonlinear and time-varying system of PID control [19], fuzzy control [20] and extremum seeking control [21] based on the optimal slip point to obtain the ideal clamping force in real time. Actual driving conditions are complex and changeable to retain the vehicle in its best state. Thus, accurate recognition of driver intention is necessary. However, many factors are not fully considered and the control results are not particularly ideal. The optimization effect can be improved, which is by determining the target speed ratio based on the accelerator pedal opening degree representing the driver intent, tracking control is added and the driving experience is verified according to different types of drivers [22-25]. This optimization method improves the transmission efficiency to a certain extent, but ignores the CVT advantages that can be combined with the engine to achieve joint optimization control and dramatically improve the transmission.

Currently, multi-objective control problems of complex nonlinear system in automotive research are widely solved using model predictive control (MPC) [26-28], because of its online prediction [29], rolling in real-time optimization [30] and before and after feedback correction $[31,32]$.

In the present study, the main contributions can be summarised as follows.
(1) A novel engine and transmission joint control idea is proposed by considering the slip rate and driving intention, and a joint controller is designed based on MPC to improve the transmission efficiency.

(2) In the controller, ratio change rate and slip rate change are creatively taken as the state variables, and the ideal slip rate is used as the optimization tracking target.

(3) The intelligent optimization method by MPC can improve the efficiency for automotive of CVT by $9.12 \%-9.35 \%$.

This paper is structured as follows. Section 2 presents the model and experiment for the belt CVT. Section 3 discusses the driver intention. Section 4 proposes the comprehensive optimization method in slip mode while Section 5 describes the drum test. Finally, Section 6 presents the conclusions. The diagram of overall control strategy is shown in the Figure 3.

\section{Configuration of the Model and Experiment System}

The principle of CVT includes a speed change mechanism and a hydraulic system, in which the former is composed of two pulleys and metal belt that is clamped under the action of the hydraulic driving force to transmit torque. If the working radius is fixed, then the ability of the transmission mechanism to transmit torque is determined by the friction coefficient and the pulley. If the clamping force continues to decrease, then the friction between the metal belt and the cone surface of the pulley fails to meet the torque transmission requirements, resulting in slip between the pulleys. The degree of slip is described by the slip rate.

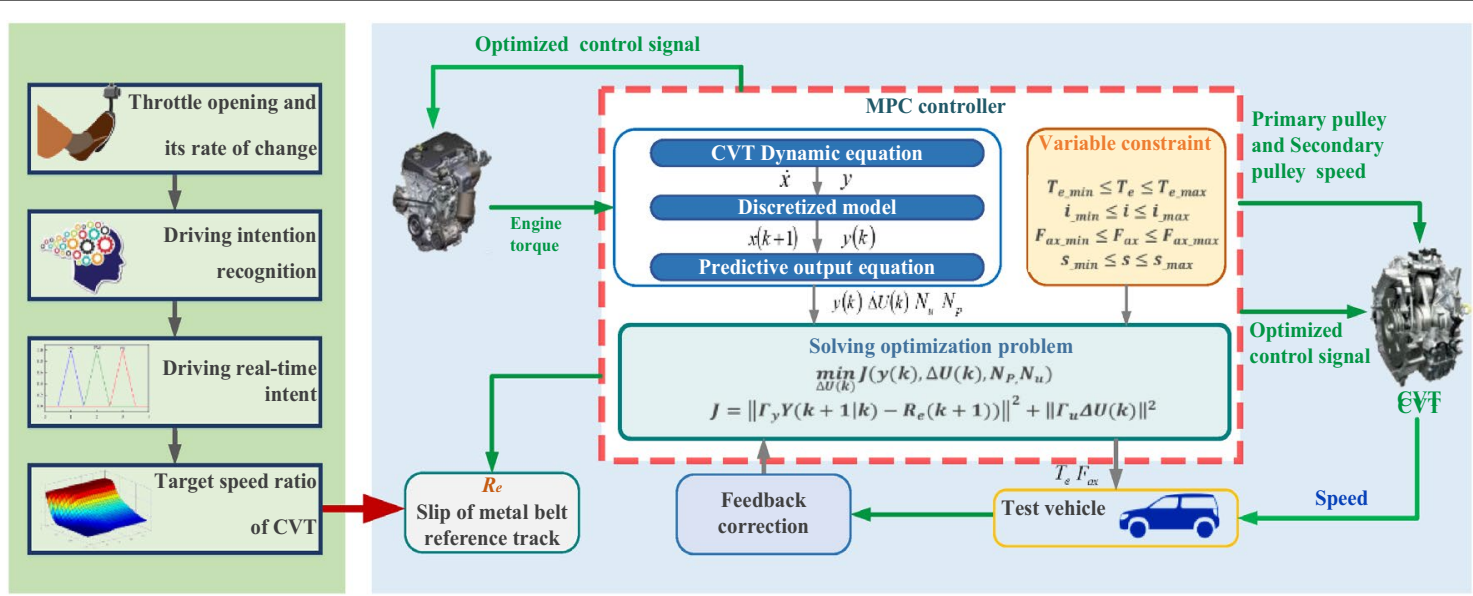

Figure 3 Diagram of overall control strategy 


\subsection{Sliding Dynamic Model of CVT}

The vehicle transmission system is simplified to facilitate modelling. The transmission shaft connecting the two cone discs is regarded as a rod and the arrow direction is the positive direction of CVT. Figure 4 shows the CVT transmission.

The left side means inertia change of the powertrain and vehicle while the right side means net torque at output shaft. The dynamic equation is established and gear ratio change rate is also considered for precise control.

$$
\begin{aligned}
& T_{e}-T_{\text {in }}=I_{e} \dot{\omega}_{e}, \\
& T_{\text {out }}=T_{\text {in }} i_{c v t} \eta_{c v t}, \\
& T_{d}=T_{\text {out }} i_{0} \eta_{0}, \\
& T_{d}-T_{r}=I_{v} \dot{\omega}_{v}, \\
& T_{\text {in }}-T_{p}=J_{p} \dot{\omega}_{p}, \\
& T_{s}-T_{\text {out }}=J_{s} \dot{\omega}_{s}, \\
& \omega_{e}=\omega_{v} i_{c v t} i_{0} .
\end{aligned}
$$

The relation between vehicle acceleration and change rate of speed ratio can be obtained by taking the derivative of Eq. (7) below.

$$
\dot{\omega}_{e}=i_{c v t} i_{0} \dot{\omega}_{v}+i_{0} \omega_{v} \dot{i}_{c v t} .
$$

Following Eq. (8) shows converting the model of CVT and Eqs. (1), (2) and (4) are implemented,

$$
\dot{i}_{c v t}=\frac{T_{e}-T_{i n}}{I_{e} i_{0} \omega_{v}}-i_{c v t}\left(\frac{T_{d}-T_{r}}{I_{v} \omega_{v}}\right),
$$

where $T_{e}$ represents the engine torque; $T_{i n}$ is the input torque of transmission; $T_{\text {out }}$ is the output torque of transmission; $I_{e}$ is the flywheel moment of inertia; $i_{c v t}$ is the ratio of CVT; $i_{0}$ is the ratio of main reducer $\eta_{c v t}$ is transmission efficiency of CVT; $\eta_{0}$ is transmission efficiency

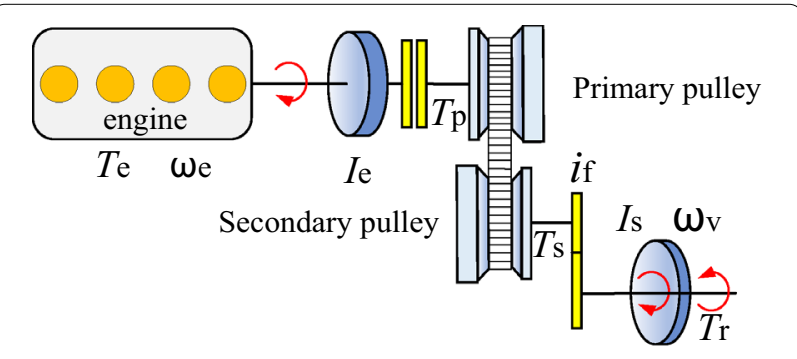

Figure 4 Transmission of CVT system of main reducer; $T_{r}$ is driven shaft; $T_{d}$ is drive torque of wheels; $I_{v}$ is the equivalent moment of inertia of the output shaft; and $\omega_{v}$ is the wheel angular velocity. $\omega_{e}$ is the angular velocity of the engine crankshaft; and $\dot{\omega}_{e}$ is the engine crankshaft angular acceleration.

The actual speed ratio $i$ and theoretical speed ratio $i_{g}$ of CVT are defined by Eqs. (10)-(12):

$$
\begin{aligned}
& i=\frac{\omega_{p}}{\omega_{s}}, \\
& i_{g}=\frac{R_{s}}{R_{p}} .
\end{aligned}
$$

Combining Eqs. (10) and (11), the slip rate can be expressed as

$$
s=\frac{\omega_{p} R_{p}-\omega_{s} R_{s}}{\omega_{p} R_{p}}=1-\frac{i_{g}}{i},
$$

where $R_{p}$ and $R_{s}$ are the radii of passive and driving pulleys, respectively; $i_{g}$ and $i$ are the theoretical and actual speed ratios, respectively; and $\omega_{s}$ is the angular velocity of driving pulley; $\omega_{p}$ is the angular velocity of primary pulley.

The slip rate and speed ratio are obtained by derivations of Eqs. (13) and (14), respectively.

$$
\begin{aligned}
& \frac{\mathrm{d} s}{\mathrm{~d} t}=\frac{i_{g}}{i^{2}} \frac{\mathrm{d} i}{\mathrm{~d} t}, \\
& \frac{\mathrm{d} i}{\mathrm{~d} t}=\frac{\dot{\omega}_{p} \omega_{s}-\omega_{p} \dot{\omega}_{s}}{\omega_{s}^{2}} .
\end{aligned}
$$

The dynamic equations of passive and driven pulleys of CVT are thus

$$
\begin{aligned}
& \dot{\omega}_{p}=\frac{T_{\text {in }}-T_{p}}{J_{p}}, \\
& \dot{\omega}_{s}=\frac{T_{s}-T_{\text {out }}}{J_{s}} .
\end{aligned}
$$

Friction theory posits that

$$
\begin{aligned}
& T_{p}=\frac{2 F_{s} R_{p} \mu}{\cos \lambda}, \\
& T_{s}=\frac{2 F_{s} R_{s} \mu}{\cos \lambda} .
\end{aligned}
$$

Substituting Eqs. (14)-(16) and Eqs. (17), (18) into Eq. (13) can obtain Eq. (19), as 


$$
\begin{aligned}
\frac{\mathrm{d} s}{\mathrm{~d} t}= & \frac{1}{\omega_{p}}\left[-\frac{2 F_{s} R_{s} \mu(s) i_{g}}{J_{s} \cos (\lambda)}+\frac{T_{\text {out }} i_{g}}{J_{s}}\right] \\
& +\frac{(1-s)}{\omega_{p}}\left[-\frac{2 F_{s} R_{s} \mu(s)}{J_{p} \cos (\lambda)}+\frac{T_{\text {in }}}{J_{p}}\right],
\end{aligned}
$$

where $T_{p}$ is the input torque of passive pulley and $T_{s}$ is the output torque of driving pulley; $J_{P}$ is a moment of inertia of the input and $J_{s}$ is a moment of inertia of the output; $\lambda$ is the cone angle between generatrix perpendicular and the axis of pulley surface; $F_{s}$ is the clamping force of driving pulley; $s$ is slip rate; and $\mu_{\mathrm{s}}$ is the variation function of friction factor with slip rate.

\subsection{Experimental Procedure}

The CVT transmission system independently developed by China is used as the research object. Figure 5 shows the designed clamping force test bench. During the test, the cylinder pressures of the passive and driven pulleys are assumed to be all closed-loop, controlled with a frequency of $100 \mathrm{~Hz}$ and a period of $20 \mathrm{~ms}$. The test is based on the following steps.

(1) The target speed of the drive motor is $1000 \mathrm{r} / \mathrm{min}$ and the target torque is $40 \mathrm{~N} \cdot \mathrm{m}$. Geometric speed ratio adopts mechanical limit method and fixed ratio position at 2.432 .

(2) The pressure of the driven cylinder is reduced from 4.1 MPa to 0.1 MPa intervals. The actual speed ratio, geometric speed ratio, transmission efficiency, and slip rate are then recorded. When the slip rate overtakes $4.5 \%$ as detected by TCU software that the system automatically enters the protection program state.

(3) Fix the geometric ratio to decrease from 2.432 to 0.419 . Then repeat step (2).

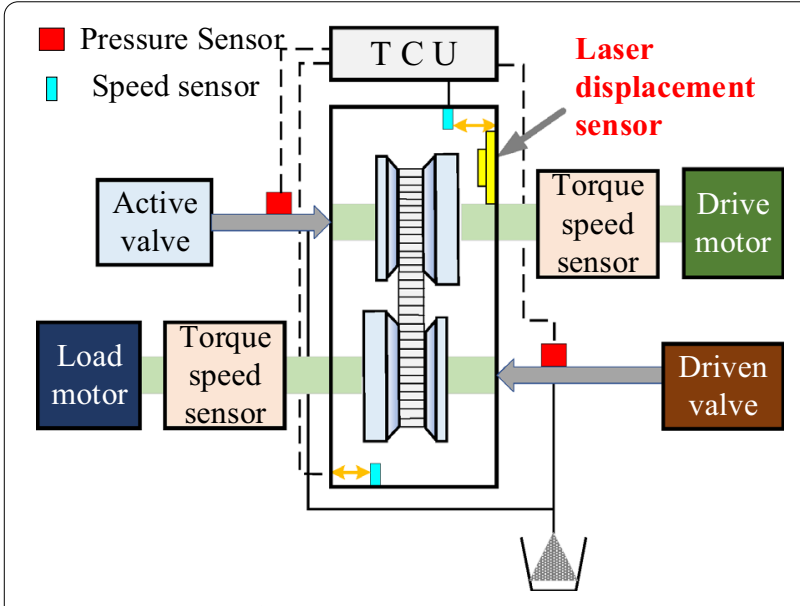

Figure 5 Diagram of clamping force bench test
(4) Set the speed of the drive motor for $400 \mathrm{r} / \mathrm{min}$ intervals from $1000 \mathrm{r} / \mathrm{min}$ to $6000 \mathrm{r} / \mathrm{min}$. Then, repeat steps (1)-(3).

(5) Set the torque of the drive motor for $20 \mathrm{~N} \cdot \mathrm{m}$ intervals from $40 \mathrm{~N} \cdot \mathrm{m}$ to $130 \mathrm{~N} \cdot \mathrm{m}$. Then repeat steps $(1)-(4)$.

The entire process is analysed through the above test, and the best slip rate and ratio of each point are fitted to form the best slip curve in Figure 6 .

When the slip rate is small, the slip rate and the friction coefficient show a linear proportional relationship, that is, the friction coefficient increases with the slip rate. When the friction coefficient reaches its peak and gradually declines, the slip rate continues to increase. Therefore, the optimal slip rate corresponds to the maximum friction coefficient at different speed ratios, and can be obtained by crossing the full ratio ranges and dividing equally, fitting the optimal slip ratio data at different ratios.

\section{Driver Intent Decision}

\subsection{Engine Model}

A $1.48 \mathrm{~L}$, 4-cylinder engine is used for this research. The engine efficiency and torque within the range 500-6000 r/ min and 30-134 N.m, respectively. Relevant data are obtained from the engine steady state test and used to determine the shape of the fuel consumption map. Figure 7 shows a $3 \mathrm{D}$ representation of the steady-state engine output torque model. With the aim to avoid multiple local maxima in the initial data set, the cubic spline interpolation method is used to smooth the parameters and obtain a working surface while retaining realistic characteristics within the numerical optimization. Figure 8 shows a 3D representation of the engine map.

However, the output characteristics of the engine is affected by the change of the mixture concentration. The engine under unsteady state condition differs from steady conditions, thereby the correction coefficient $\gamma$ is

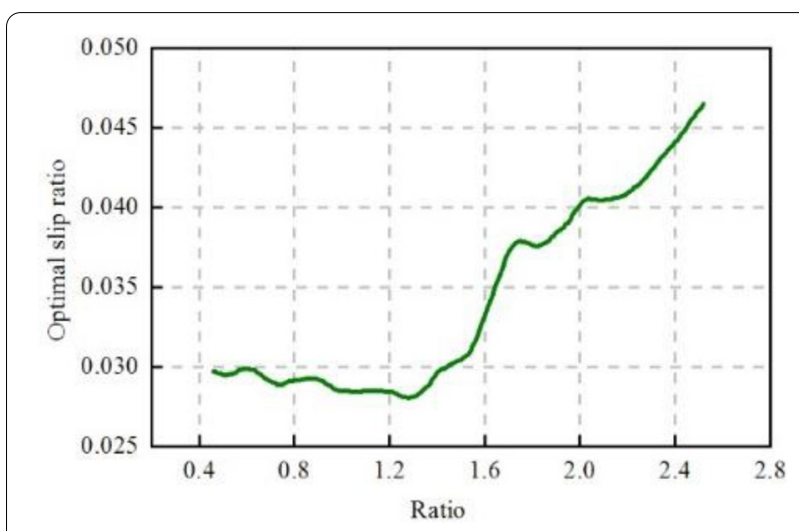

Figure 6 Relationship between optimal slip and ratio 


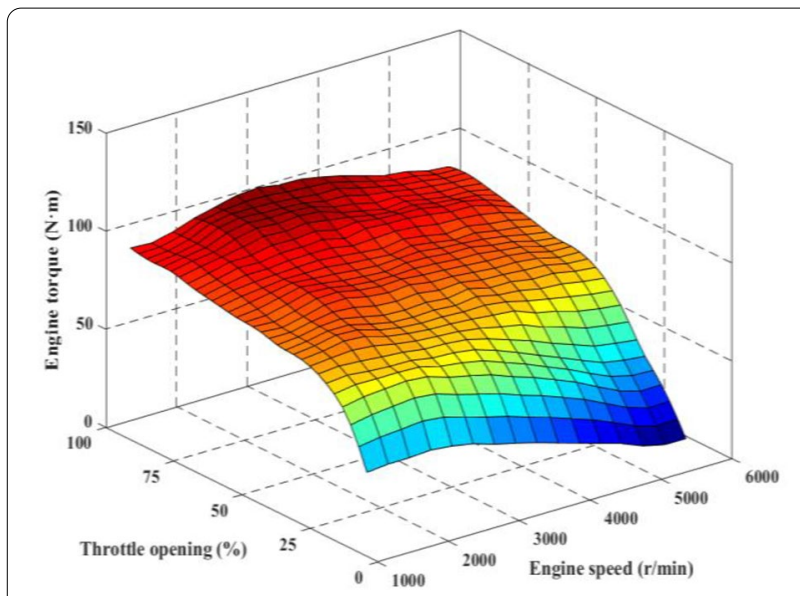

Figure 7 Steady-state engine fuel consumption map

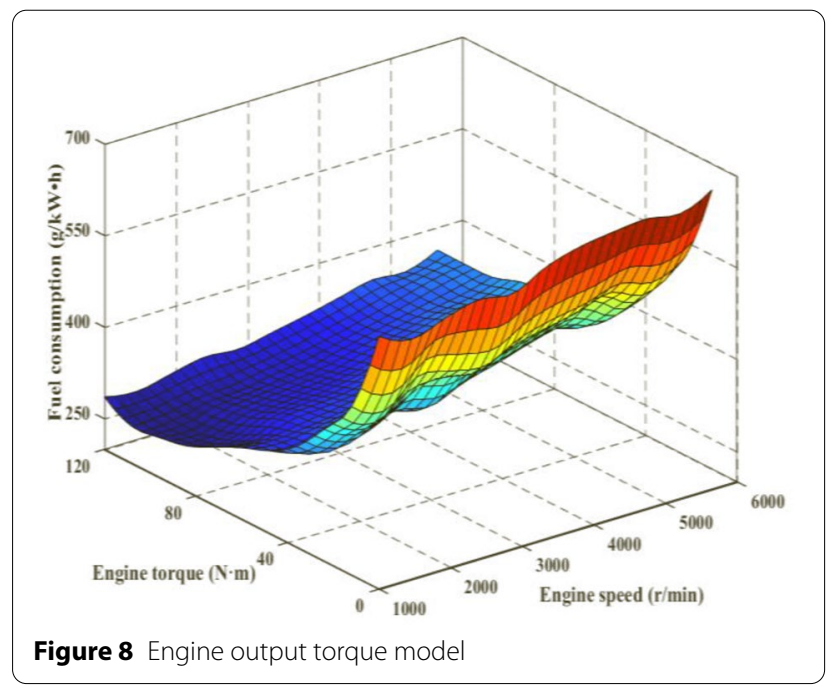

introduced to modify the engine torque. Eq. (20) obtains the modified dynamic output torque as

$$
T_{e}=T_{e w}\left(1-\gamma \frac{\mathrm{d} \omega_{e}}{\mathrm{~d} t}\right),
$$

where $T_{e w}$ is the steady-state output torque of the engine and $\gamma$ is the torque drop coefficient (0.08).

\subsection{Identify Driver Intention}

CVT efficiency is determined using bench test data and is most dependent on CVT ratio. When the vehicle throttle opening is constant, the ratio is precisely controlled to ensure that the engine output power and running resistance can be optimally matched according to the driver intention in real time. Eq. (21) obtains the CVT ratio as

$$
i=\frac{R_{s}}{R_{p}}=\frac{n_{\text {in }}}{n_{\text {out }}},
$$

where $n_{\text {in }}$ is input shaft speed and $n_{\text {out }}$ is output shaft speed. The maximum and minimum ratios applied to the CVT are

$$
\begin{aligned}
& i=\frac{R_{s \_ \text {max }}}{R_{p \_ \text {min }}}, \\
& i=\frac{R_{s_{-} \min }}{R_{p_{-} \max }} \underset{\text { min }}{ } .
\end{aligned}
$$

Three constraints come from restricting the CVT target ratio, which are

$$
i_{\text {obj }}=\left\{\begin{array}{c}
i_{\text {max }},\left(n_{\text {in }} / n_{\text {out }}>i_{\text {max }}\right) \\
n_{\text {in }} / n_{\text {out }},\left(i_{\text {max }}>n_{\text {in }} / n_{\text {out }}>i_{\text {min }}\right) \\
i_{\text {min }},\left(n_{\text {in }} / n_{\text {out }}<i_{\text {max }}\right)
\end{array}\right.
$$

The ratio can also be expressed in Eq. (25),

$$
i=\frac{0.377 r_{w} n_{e}}{v i_{0}},
$$

where $r_{w}$ is the wheel radius; $n_{e}$ is engine speed; and $v$ is driving speed.

The equations of the target rate constraint applied in the movement structure and the shift rate limits are a function of CVT ratio, as shown in Figure 9.

Thus, the engine throttle opening and vehicle speed are fixed. Figures 10, 11 show two 3D representations of the best economy and dynamic of target ratio maps.

The driver's evaluation of the vehicle driving performance is subjective, and reflects the degree of conformity for the actual vehicle response and driver expectations. Different driving habits and operating conditions have varied requirements for vehicle driving performance. However, in general, driver expectations of vehicle response can be described as smooth and

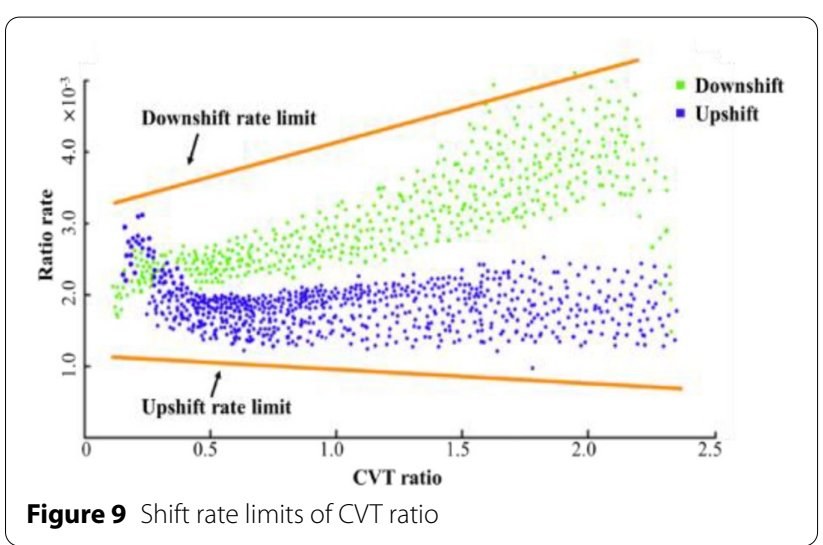




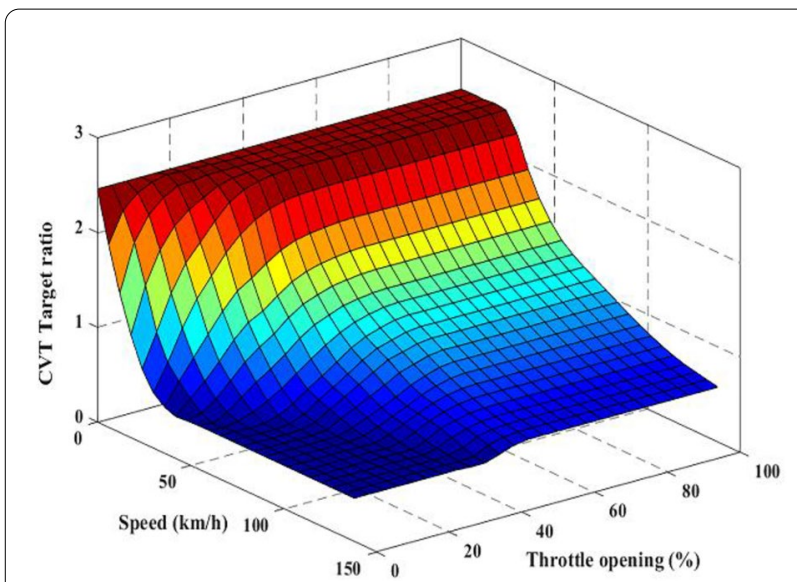

Figure $103 \mathrm{D}$ representation of the best economy of target ratio

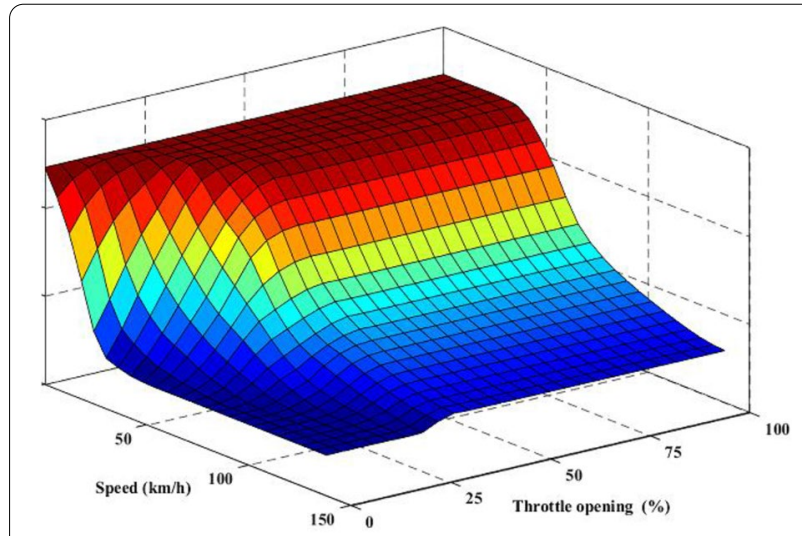

Figure 11 3Drepresentation of the best dynamic of target ratio

fast input response to throttle opening, consistent with expected psychological expectations, and repeatable. Therefore, the dynamic and economic mode alone cannot fully reflect the driver intention in real time. Determining the target ratio of the vehicle in standard mode is necessary. The target engine speed in standard mode can be expressed as Eq. (26)

$$
n_{m e}=k\left(n_{s e}-n_{e e}\right)+n_{e e},
$$

where $n_{m e}$ is the target ratio of engine in standard mode; $n_{s e}$ is the target ratio of engine in dynamic mode; $n_{e e}$ is the target ratio of engine in economic mode; and $k$ is intent parameter of driving set between $0-1$ to change continuously. Figure 12 shows the target engine speed.

In actual driving, the accelerator pedal opening change rate can better reflect the driver's real-time demand for vehicle dynamics. Therefore, the driving intention parameter can be expressed as

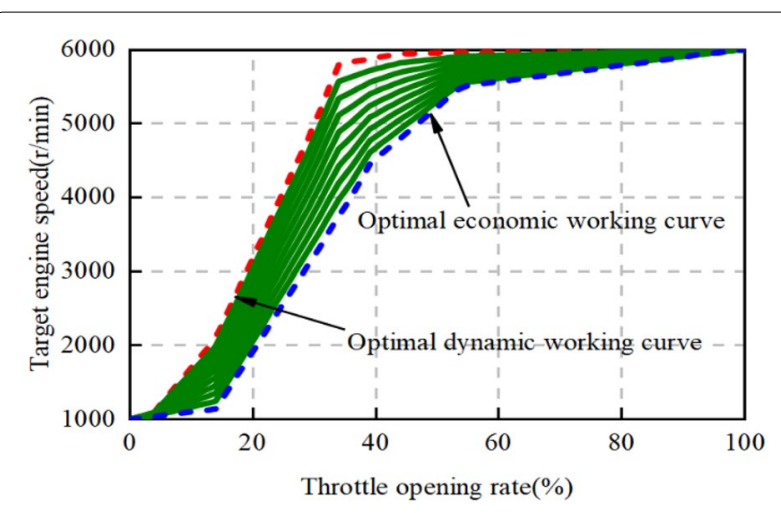

Figure 12 Engine speed regulation characteristic curve in standard mode

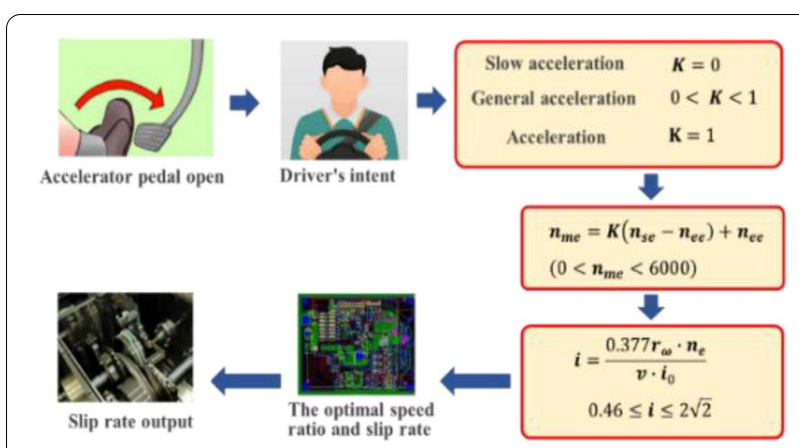

Figure 13 Driver intent

$$
k=f(\mathrm{~d} \theta / \mathrm{d} t),(0<k<1)
$$

where $\theta$ is accelerator pedal opening.

Vehicle acceleration is slow when $k=0$ and general when $0<k<1$. Figure 13 shows the driver's operating intention when vehicle acceleration is $k=1$.

The accelerator pedal opening degree and its rate of change are selected as the basis for recognition of acceleration intention. When the vehicle brakes or decelerates, the driver has no demand for the vehicle power, and the engine working curve is assumed equivalent to the best economic curve. The input accelerator pedal opening and rate of change and the output variable acceleration intention are blurred. The domain of accelerator pedal opening is set as $[0,100]$ and the corresponding fuzzy subset is $\{\mathrm{PS}, \mathrm{PM}, \mathrm{PB}\}$. The domain of rate change of accelerator pedal opening is set as $[-100,100]$ and the corresponding fuzzy subset is $\{\mathrm{N}, \mathrm{PS}, \mathrm{PM}, \mathrm{PB}\}$. The corresponding fuzzy subset of the accelerator pedal opening of input and its rate of change is $\{P S, P M, P B\}$. Figure 13 shows the membership function. Final fuzzy inference system uses the Mamdani algorithm and centre of gravity method for back fuzzy. Table 1 shows the fuzzy inference rules. 
Table 1 Fuzzy inference rules

\begin{tabular}{llllll}
\hline Item & \multicolumn{5}{l}{$\begin{array}{l}\text { Change of rate for accelerator pedal opening } \\
\text { displacement }\end{array}$} \\
\cline { 2 - 6 } & & N & PS & PM & PB \\
\hline Accelerator & PS & PS & PS & PM & PB \\
Pedal & PM & PS & PM & PM & PB \\
Displacement & PB & PS & PM & PB & PB \\
\hline
\end{tabular}

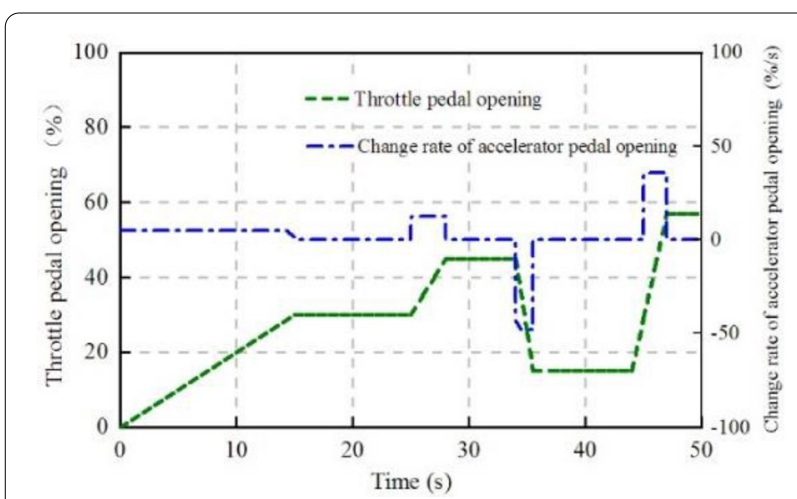

Figure 14 Curve of the accelerator pedal opening and its change rate

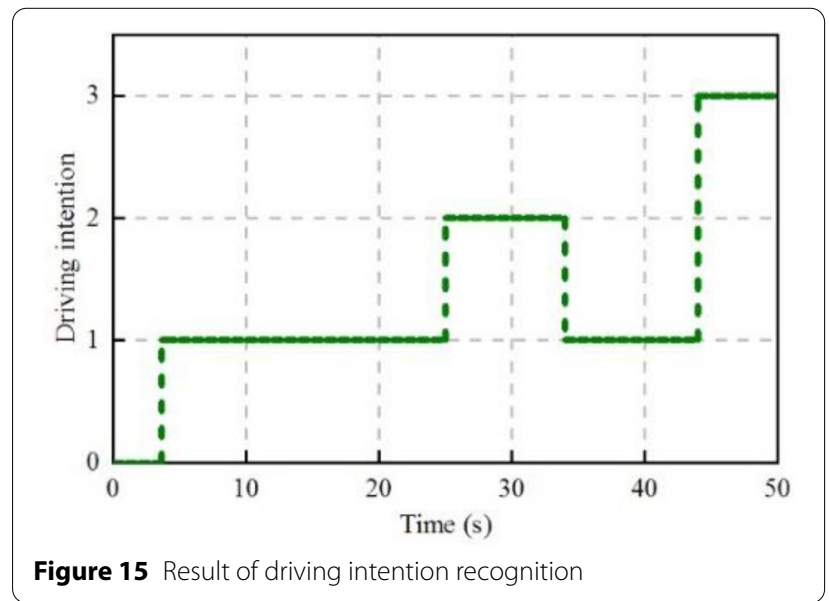

Figures 14, 15 show the vehicle rate of change for accelerator pedal opening curve and recognition result of driver intention, respectively, to simulate and verify the driving intent model. Figure 11 shows that in $0-25 \mathrm{~s}$, the accelerator pedal opening increases from $0 \%$ to $30 \%$, then remains steady with rate change maintained at $5 \% / \mathrm{s}$ within $0-15 \mathrm{~s}$. The accelerator pedal opening remains unchanged and returns to $0 \% / \mathrm{s}$ within 15-25 s. In 25-34 s, the accelerator pedal opening increases from $30 \%$ to $45 \%$, then remains steady with rate change maintained at $12.5 \% / \mathrm{s}$ within $25-28 \mathrm{~s}$. The accelerator pedal opening remains unchanged and returns to $0 \% / \mathrm{s}$ within 15-25 s. In 34-35.5 s, the accelerator pedal opening decreases from $45 \%$ to $15 \%$ with rate change maintained at $-48 \% / \mathrm{s}$, then remains unchanged. In $44-50 \mathrm{~s}$, the accelerator pedal opening increases to $57 \%$ then remains steady at $35.5 \% / \mathrm{s}$ and decreases to $0 \% / \mathrm{s}$.

The vehicle accelerator pedal opening and its change rate are: small between $0-25 \mathrm{~s}$ and 34-44 s, with slow acceleration; increases between 25-34 s, with general acceleration; and large between 44-50 s, with emergency acceleration. According to the above acceleration recognition results, the controller accurately recognises the driver intention, and fuzzy controller has good effectiveness.

\section{Proposed Comprehensive Optimization Method in Slip Mode}

\subsection{State Space Equation of CVT}

The slip $s$ and ratio $i$ are defined as state variables $x$; clamping force $F_{s}$ and torque of engine $T_{e}$ are controlled to output as $u$; slip $s$ and ratio $i$ are predicted to output as $y$; and input torque $T_{i n}$ and output torque $T_{\text {out }}$ of CVT are disturbance variables $d$. The incremental model is as follows:

$$
\begin{aligned}
& \dot{x}(t)=A x(t)+B u(t)+B_{d} d(t), \\
& y(t)=C x(t),
\end{aligned}
$$

where

$$
\begin{aligned}
& x=\left[\begin{array}{ll}
i & s
\end{array}\right]^{\mathrm{T}}, \\
& u=\left[\begin{array}{ll}
F_{s} & T_{e}
\end{array}\right]^{\mathrm{T}}, \\
& y=\left[\begin{array}{ll}
i & s
\end{array}\right]^{\mathrm{T}}, \\
& d=\left[\begin{array}{ll}
T_{\text {in }} & T_{\text {out }}
\end{array}\right]^{\mathrm{T}}, \\
& A=\left[\begin{array}{cc}
\frac{T_{r}-T_{d}}{I_{\nu} \omega_{\nu}} & 0 \\
0 & \frac{2 F_{s} R_{s} \mu(s)}{J_{p} \omega_{p} \cos \lambda}-\frac{T_{i n}}{J_{p} \omega_{p}}
\end{array}\right], \\
& B=\left[\begin{array}{cc}
\frac{1}{-2 R_{s} \mu(s) i_{g}} & 0 \\
\frac{J_{s} \omega_{p} \cos \lambda}{I_{2}}+\frac{-2 R_{s} \mu(s)}{I_{p} \omega_{p} \cos \lambda} & 0
\end{array}\right], \\
& B_{d}=\left[\begin{array}{cc}
-\frac{1}{I_{e} i_{0} \omega_{0} \omega_{\nu}} & 0 \\
\frac{1}{J_{p} \omega_{p}} & \frac{i_{g}}{J_{s} \omega_{p}}
\end{array}\right],
\end{aligned}
$$




$$
C=\left[\begin{array}{ll}
1 & 0 \\
0 & 1
\end{array}\right]
$$

The linearized friction coefficient $\mu(s)$ can be expressed as Eq. (28) to facilitate the controller design:

$$
\mu(s)=k_{1} s+k_{2} .
$$

The CVT state space equation is linearized at $x=s_{0}$ as the operating point,

$$
\begin{aligned}
& \delta \dot{x}(t)=A_{0} \delta x(t)+B_{0} \delta u(t)+B_{d 0} \delta d(t), \\
& \delta y(t)=C_{0} \delta x(t),
\end{aligned}
$$

where $\delta x=x-x_{0}, \delta u=u-u_{0}, \delta d=d-d_{0}$.

\subsection{Joint Controller Design}

The controller is realised by discretising the state space equation for the sampling period $T_{s}$,

$$
\begin{aligned}
& x(k+1)=A_{c} x(k)+B_{c} u(k)+B_{d c} d(k), \\
& y(k)=C x(k),
\end{aligned}
$$

where $A_{c}=e^{A T_{s}}, B_{c}=\int_{0}^{T_{s}} e^{A \tau} \mathrm{d} s \cdot B$,

$$
B_{d c}=\int_{0}^{T_{s}} e^{A \tau} \mathrm{d} s \cdot B_{d} .
$$

Integral is introduced to eliminate the static error generated during the clamping force control, and the discretised state model is rewritten as the following incremental model forms,

$$
\begin{aligned}
& \Delta x(k+1)=A_{c} \Delta x(k)+B_{c} \Delta u(k)+B_{d c} \Delta d(k), \\
& y(k)=C \Delta x(k)+y(k-1),
\end{aligned}
$$

where

$$
\begin{aligned}
& \Delta x(k)=x(k)-x(k-1) ; \\
& \Delta u(k)=u(k)-u(k-1) ; \\
& \Delta d(k)=d(k)-d(k-1) .
\end{aligned}
$$

The prediction time domain NP contains the main dynamic part of the object. The smaller the NP is, the faster it is, the more unstable it is, the lower the real-time performance and the slower the response is. Considering the stability and real-time performance, the value of NP is 10. The smaller the control time-domain NC is, the slower the control speed is, the better the robustness is. The larger the maneuverability is, the stronger the stability is. Considering the robustness and maneuverability, the prediction and control time domains are defined as $N_{p}=10, N_{u}=2$, respectively.

Using $\Delta x(k)$ as the starting point for the prediction of the system, the state at times $k+1$ to $k+N_{p}$ can be predicted as:

$$
\begin{aligned}
& \Delta x(k+1 \mid k)=A_{c} \Delta(k)+B_{c} \Delta u(k)+B_{d c} \Delta d(k), \\
& \Delta x(k+2 \mid k)=A_{c} \Delta(k+1 \mid k)+B_{c} \Delta u(k+1)+B_{d c} \Delta d(k+1) \\
& =A_{c}^{2} \Delta x(k)+A_{c} B_{c} \Delta u(k)+B_{c} \Delta u(k+1)+A_{c} B_{d c} \Delta d(k) \text {, } \\
& \Delta x(k+3 \mid k)=A_{c} \Delta x(k+2 \mid k)+B_{c} \Delta u(k+2)+B_{d c} \Delta d(k+2) \\
& =A_{c}^{3} \Delta x(k)+A_{c}^{2} B_{c} \Delta u(k)+A_{c} B_{c} \Delta u(k+1)+B_{c} \Delta u(k+2)+A_{c}^{2} B_{d c} \Delta d(k), \\
& \Delta x\left(k+N_{u} \mid k\right)=A_{c} \Delta x\left(k+N_{u}-1 \mid k\right)+B_{c} \Delta u\left(k+N_{u}-1\right)+B_{d c} \Delta d\left(k+N_{u}-1\right) \\
& =A_{c}^{N_{u}} \Delta x(k)+A_{c}^{N_{u}-1} B_{c} \Delta u(k)+A_{c}^{N_{u}-2} B_{c} \Delta u(k+1)+\cdots \\
& +B_{c} \Delta u(k+m-1)+A_{c}^{N_{u}-1} B_{d c} \Delta d(k) \\
& \cdot \\
& \Delta x\left(k+N_{p} \mid k\right)=A_{c} \Delta x\left(k+N_{p}-1 \mid k\right)+B_{c} \Delta u\left(k+N_{p}-1\right)+B_{d c} \Delta d\left(k+N_{p}-1\right) \\
& =A_{c}^{N_{p}} \Delta x(k)+A^{N_{p}-1} B_{c} \Delta u(k)+A_{c}^{N_{p}-2} B_{c} \Delta u(k+1)+\cdots \\
& +A_{c}^{N_{p}-N_{u}} B_{c} \Delta u\left(k+N_{u}-1\right)+A_{c}^{N_{p}-1} B_{d c} \Delta d(k),
\end{aligned}
$$


where $k+i \mid k$ represents the prediction of $k+i$ at sampling time $k$, and $k$ after the symbol "|" represents the current sampling time.

Similarly,

$$
\begin{aligned}
& y(k+1 \mid k)=C \Delta x(k+1 \mid k)+y(k) \\
& =C A_{c} \Delta x(k)+C B_{c} \Delta u(k)+C B_{d c} \Delta d(k)+y(k), \\
& y(k+2 \mid k)=C \Delta x(k+2 \mid k)+y(k+1 \mid k) \\
& =\left(C A_{c}^{2}+C A_{c}\right) \Delta x(k)+\left(C A_{c} B_{c}+C B_{c}\right) \Delta u(k)+ \\
& C B_{c} \Delta u(k+1)+\left(C A_{c} B_{d c}+C B_{d c}\right) \Delta d(k)+y(k), \\
& \vdots \\
& y\left(k+N_{u} \mid k\right)=C \Delta x\left(k+N_{u} \mid k\right)+y\left(k+N_{u}-1 \mid k\right) \\
& =\sum_{i=1}^{N_{u}} C A_{c}^{i} \Delta x(k)+\sum_{i=1}^{N_{u}} C A_{c}^{i-1} B_{c} \Delta u\left(k+\sum_{i=1}^{N_{u}-1} C A_{c}^{i-1} B_{c} \Delta u(k+1)+\cdots\right. \\
& +C B_{c} \Delta u\left(k+N_{u}-1\right)+\sum_{i=1}^{N_{u}} C A_{c}^{i-1} B_{d c} \Delta d(k)+y(k), \\
& \vdots \\
& y\left(k+N_{p} \mid k\right)=C \Delta x\left(k+N_{p} \mid k\right)+y\left(k+N_{p}-1 \mid k\right) \\
& =\sum_{i=1}^{N_{p}} C A_{c}^{i} \Delta x(k)+\sum_{i=1}^{N_{p}} C A_{c}^{i-1} B_{c} \Delta u(k)+\sum_{i=1}^{N_{p}-1} C A_{c}^{i-1} B_{c} \Delta u(k+1)+\cdots \\
& \quad+\sum_{i=1}^{N_{p}-N_{u}+1} C A_{c}^{i-1} B_{c} \Delta u\left(k+N_{u}-1\right)+\sum_{i=1}^{N_{p}} C A_{c}^{i-1} B_{d c} \Delta d(k)+y(k) .
\end{aligned}
$$

where $r(k+i)=s(k+i), i=1,2, \cdots, N_{p}$.

Given the theoretical basis of model predictive control, the clamping force optimization problem can be described as the following objective function,

At sampling time $k$, the control input vector $\Delta U(k)$ and the predicted output vector $Y(k+1 \mid k)$ are defined as:

$$
\begin{gathered}
\Delta U(k)=\left[\begin{array}{c}
\Delta u(k \mid k) \\
\Delta u(k+1 \mid k) \\
\vdots \\
\Delta u\left(k+N_{u}-1 \mid k\right)
\end{array}\right], \\
Y(k+1 \mid k)\left[\begin{array}{c}
y(k+1 \mid k) \\
y(k+2 \mid k) \\
\vdots \\
y\left(k+N_{p} \mid k\right)
\end{array}\right],
\end{gathered}
$$

where,

$$
\begin{gathered}
\Delta u(k+i \mid k)=\left[\begin{array}{c}
\Delta F_{s}(k+i \mid k) \\
\Delta T_{e}(k+i \mid k)
\end{array}\right] \quad i=1,2, \cdots, N_{u}-1 ; \\
y(k+i \mid k)=\left[\begin{array}{c}
i(k+i \mid k) \\
S(k+i \mid k)
\end{array}\right] \quad i=1,2, \cdots, N_{p} .
\end{gathered}
$$

The reference input sequence can be defined as

$$
R_{e}(k+1)=\left[r(k+1) r(k+2) \cdots r\left(k+N_{p}\right)\right]^{\mathrm{T}},
$$

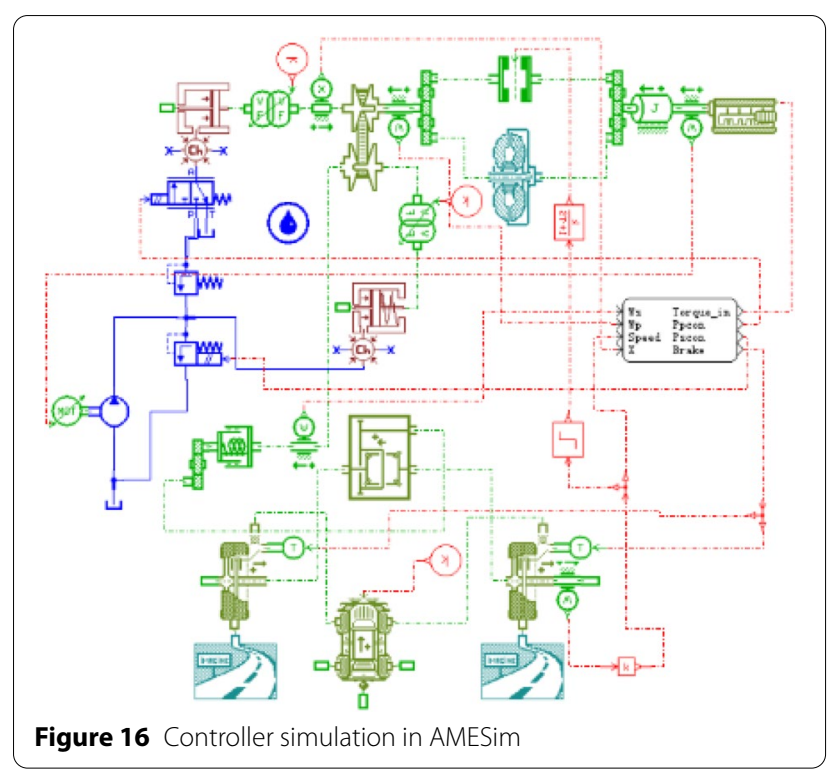




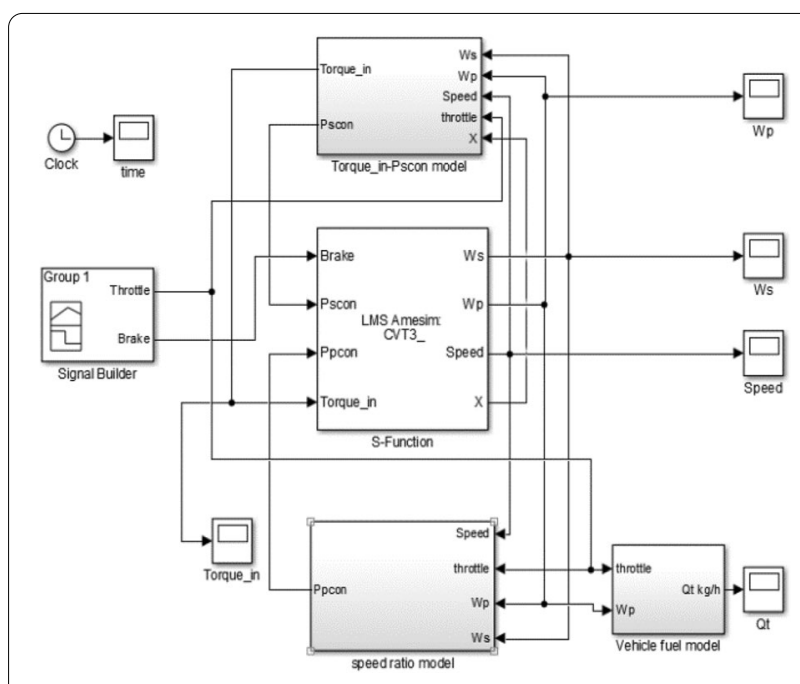

Figure 17 Controller simulation in MATLAB/SIMULINK
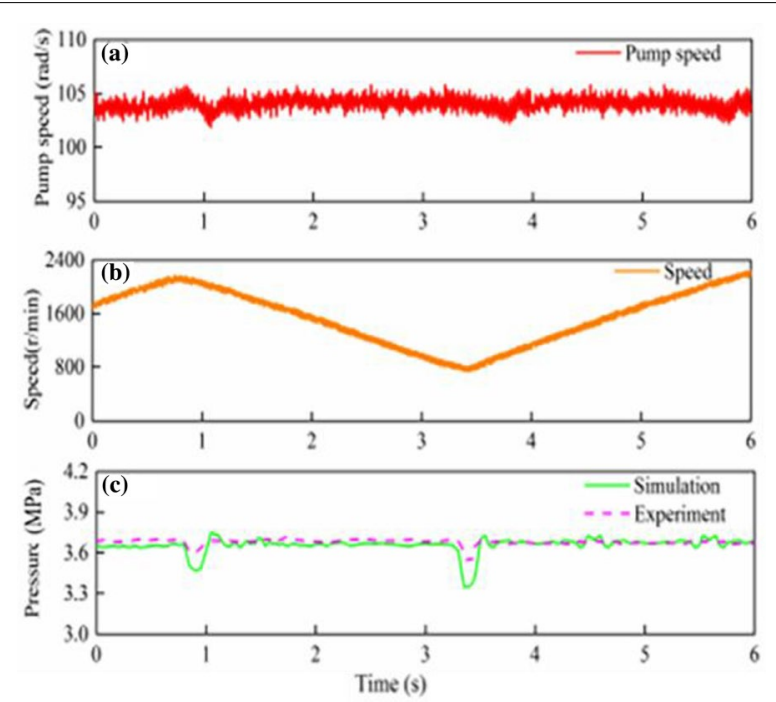

Figure 18 a Pump speed, b Speed, c Pressure

$$
\begin{aligned}
& \min _{\Delta U(k)} J\left(y(k), \Delta U(k), N_{u}, N_{p}\right), \\
& J=\left\|\Gamma_{y}\left(Y(k+1 \mid k)-R_{e}(k+1)\right)\right\|^{2}+\left\|\Gamma_{u} \Delta U(k)\right\|^{2},
\end{aligned}
$$

where

$$
\Gamma_{y}=\operatorname{diag}\left\{\gamma_{y, 1}, \cdots, \gamma_{y, N_{p}}\right\} ; \Gamma_{u}=\operatorname{diag}\left\{\gamma_{u, 1}, \cdots, \gamma_{u, N_{u}}\right\} .
$$

The slip rate tracking effect of the clamping force controller can be changed by adjusting the error weight coefficient $\Gamma_{y}$, setting $\gamma_{y, i}=0.13, i=1,2, \cdots, N_{p}$. The change rate of the clamping force can be controlled to prevent the actuator from reaching the saturation state by adjusting the control weight coefficient $\Gamma_{u}$. Set $x$ as the reference input of the slip rate as $\gamma_{u, i}=1$, $i=1,2, \cdots, N_{u}, R_{e}(k+1)$.

Defined,

$$
\begin{aligned}
& J_{1}=\| \Gamma_{y}\left(Y(k+1 \mid k)-R_{e}(k+1) \|^{2},\right. \\
& J_{2}=\left\|\Gamma_{u} \Delta U(k)\right\|^{2},
\end{aligned}
$$

where $J_{1}$ represents the square weighted value of the difference between the actual measured slip rate in the predicted time domain and the reference input and $J_{2}$ represents the square-weighted value of the amount of clamping force change in the control time domain.

Three more constraints arise from restricting the clamping force controller between a maximum and minimum predefined variable.

$$
\begin{aligned}
& T_{e_{-} \text {min }} \leq T_{e} \leq T_{e_{-} \text {max }}, \\
& i_{- \text {min }} \leq i \leq i_{-} \text {max } \\
& F_{a x \_ \text {min }} \leq F_{a x} \leq F_{a x \_ \text {max }}, \\
& s_{\_ \text {min }} \leq s \leq s_{-} \text {max. }
\end{aligned}
$$

The constrained objective function is applied to obtain the final optimization result.

\subsection{Joint Controller Design Simulation Model}

Figures 16 and 17 show simulation models built on MATLAB/SIMULINK and AMESim platforms. Simulink

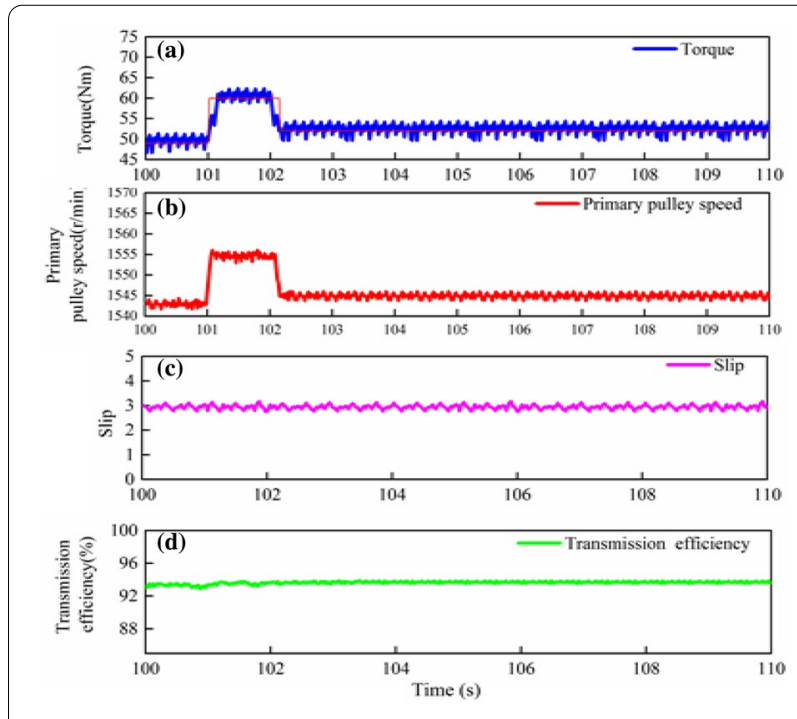

Figure 19 a Input side torque step interference, $\mathbf{b}$ Speed of primary pulley, c Slip, d CVT transmission efficiency 
includes clamping force control, speed ratio control and engine. AMESim includes CVT, vehicle, slip and hydraulics. The simulation model shows that the clamping force control module based on MPC inputs the optimised clamping force control signal to its valve through the rotary interface. Clamping is realised by controlling the secondary pulley cylinder control of precise force. The PID-based speed ratio control module applies the optimised ratio signal to its valve.

The closed-loop control experiment of the clamping force system is carried out based on the above-mentioned controller design principle. In Figure 18, the driving motor torque is $45 \mathrm{~N} \cdot \mathrm{m}$, speed ratio is 0.45 and the stable speed is $1600 \mathrm{r} / \mathrm{min}$.

During the step response test, maintain the pump speed and the driving shaft constant, the actual speed fluctuates around the controlled target value in Fig. 18a. According to the results, with the step input of the driving current of the lead solenoid valve, the speed of the primary pulley shaft shows a saw tooth change similar to a sinusoid (Fig. 18b). Moreover, comparison of the pressure response of the hydraulic system shows a good consistency of the test and simulation results (Fig. 18c).

\subsection{Robust Verification}

Based on the MPC control strategy, the torque interference on the active side mainly depends on the engine operating conditions and road surface conditions, which are divided into continuous and non-continuous interferences. Typical operating conditions of continuous interference include the vehicle transition from flat road to hill climbing sections, or from smooth to rough roads. Noncontinuous disturbances include torque shocks caused by vehicles passing through potholes or avoiding obstacles.

The robust performance analysis of the CVT system mainly depends on the system stability after a disturbance. Therefore, robust verification of the control system is necessary under non-steady-state condition. The robust verification is achieved by simulating the driver quickly stepping on the accelerator pedal to maintain speed and then lifting the pedal. The engine

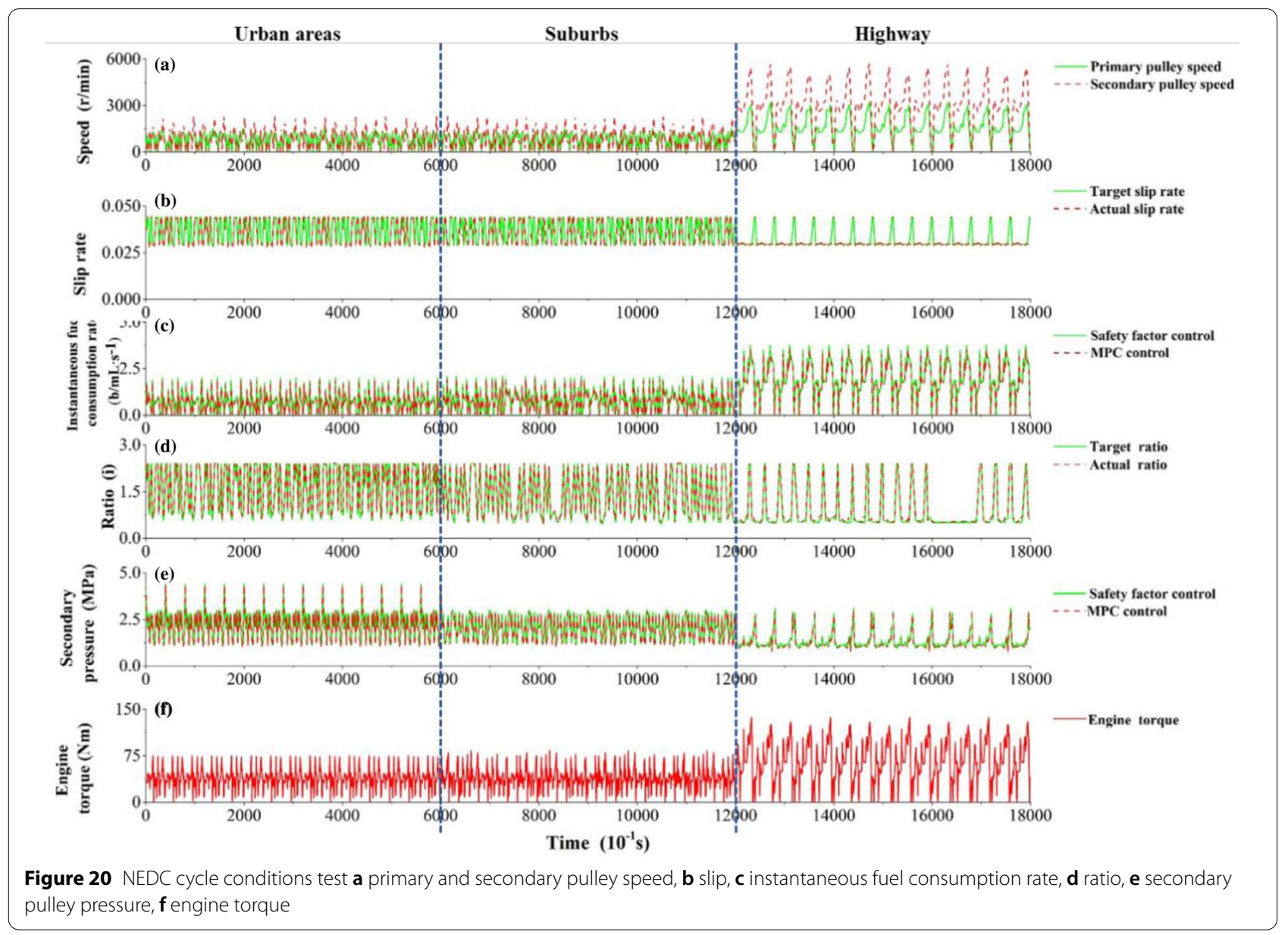




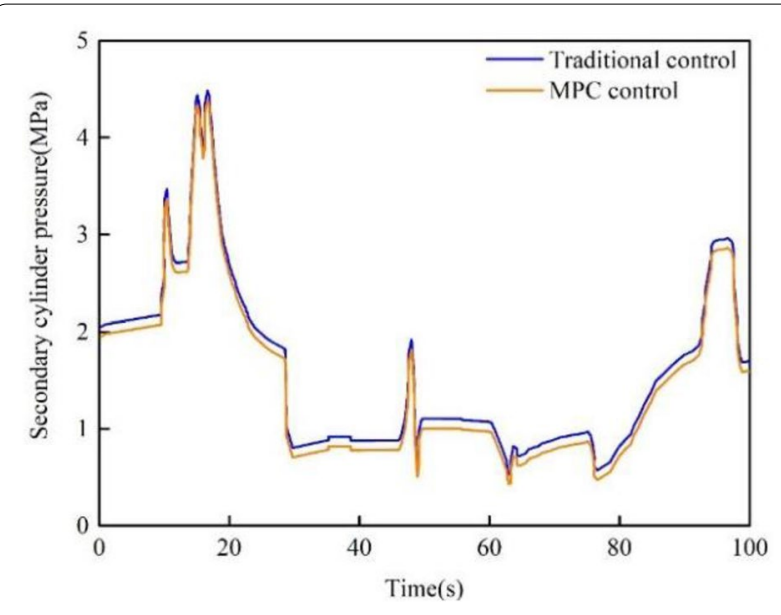

Figure $\mathbf{2 1}$ The secondary cylinder pressure comparison under comprehensive working conditions

generates step torque that remains unchanged and decreases, the value can be read directly through the engine MAP.

The robustness of the control system is further analysed. Figure 19 shows that a certain torque disturbance factor is imposed from the outside. The input side torque step disturbance in (a) shows that between 100-101 s, the torque is relatively stable without apparent fluctuations. When $t=101 \mathrm{~s}$, a stepping torque of $13 \mathrm{~N} \cdot \mathrm{m}$ shock is imposed. The input side torque produces a corresponding step change, and the torque rises from the initial value of $50-63 \mathrm{~N} \cdot \mathrm{m}$. At $102 \mathrm{~s}$, a decrease of $7 \mathrm{~N} \cdot \mathrm{m}$ step torque on CVT input side maintains the torque at $53 \mathrm{~N} \cdot \mathrm{m}$. Under the MPC, the clamping force is pre-controlled by loading a certain clamping force according to the sudden torque change. The transmission mechanism can provide the additional torque. Therefore, the active side speed rises first in the control system, and then quickly stabilises. Figure 19b shows the speed of primary pulley. After the cylinder pressure changes, the actual response follows the dynamic response faster and operates steadily with changes in external torque interference. Figure 19c and d show the changes of the slip and transmission efficiency when the torque disturbance on the input side, respectively. When the CVT input side is subjected to torque disturbance, the transmission efficiency and slip generally perform smoothly, the transmission efficiency only slightly fluctuates at the torque step, the slip is always kept within the safety threshold, and thus the transmission system remains stable. Given the above test results, the CVT control system designed in MPC has good robust performance.

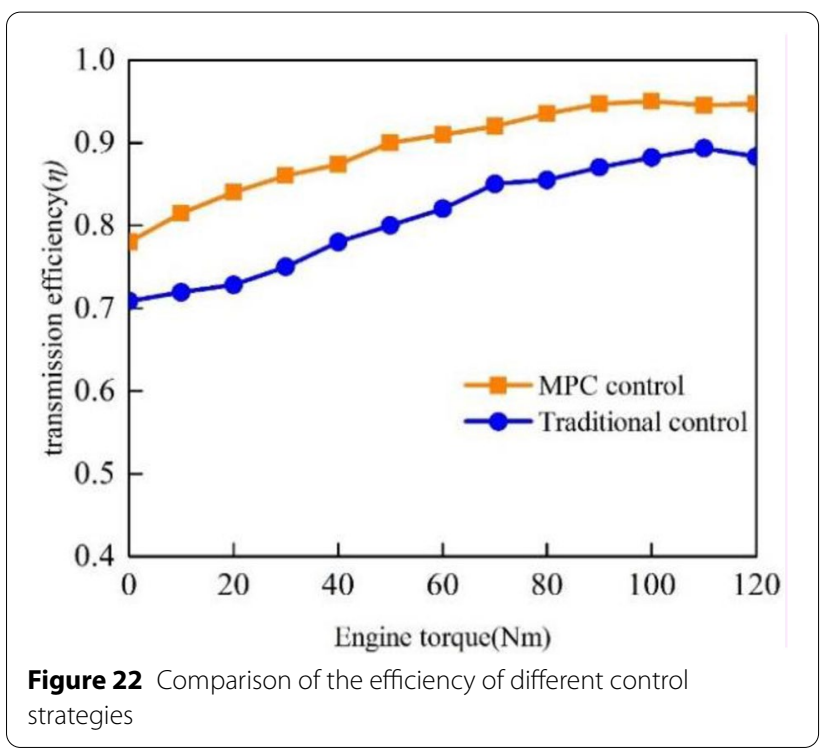

Table 2 Chassis dynamometer parameters

\begin{tabular}{ll}
\hline Parameter & Value \\
\hline Driving form & 4 WD \\
Drum size (feet) & 48 \\
Maximum vehicle speed $(\mathrm{km} / \mathrm{h})$ & 200 \\
Wheelbase adjustment range $(\mathrm{m})$ & $2.1-4.7$ \\
Maximum uniaxial load $(\mathrm{kg})$ & 4500 \\
Inertia simulation range $(\mathrm{kg})$ & $454-5400$ \\
\hline
\end{tabular}

Table 3 Test parameters

\begin{tabular}{ll}
\hline Parameter & Value \\
\hline Total mass $(\mathrm{kg})$ & 1360 \\
CVT ratio range & $0.46-2.43$ \\
Area ratio of cylinders & 2.012 \\
Engine displacement $(\mathrm{L})$ & 1.498 \\
Pulley centre distance $(\mathrm{m})$ & 0.153 \\
Cone angle of pulley $\left(^{\circ}\right)$ & 11 \\
Oil pump displacement $(\mathrm{L})$ & 9.6 \\
Metal belt length $(\mathrm{m})$ & 0.818 \\
\hline
\end{tabular}

\subsection{Simulation and Analysis of Control System}

On the basis of robust performance test analysis, the controller designed based on the model predictive control strategy and the safety factor method control strategy is compared and tested under New European Driving Cycle (NEDC) cycle conditions to ensure reliability and consistency. As a mainstream vehicle test condition, NEDC cycle operating conditions are widely used in vehicle 

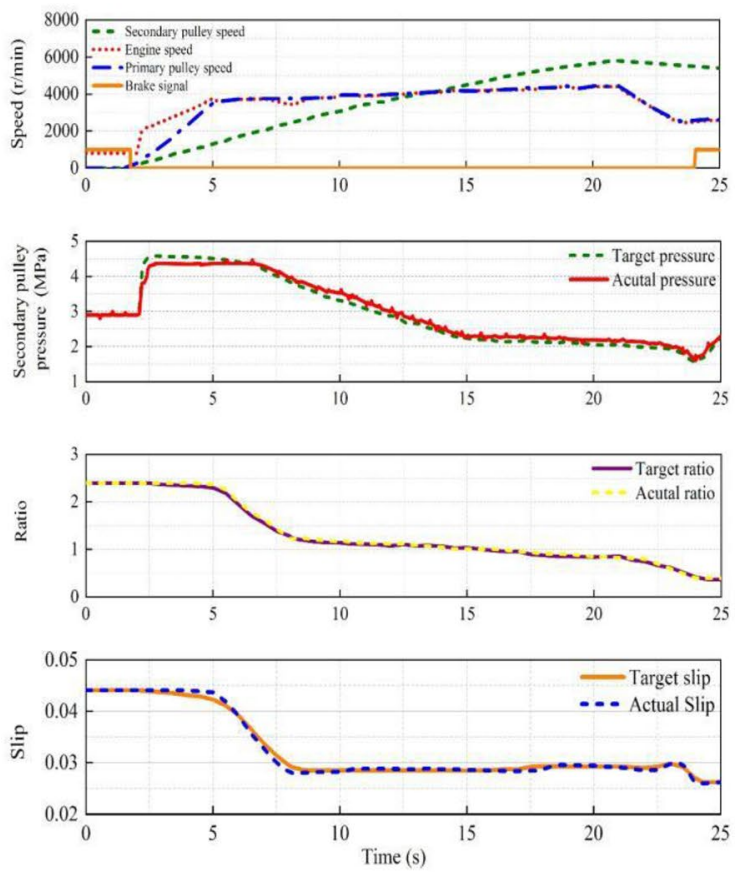

(a)
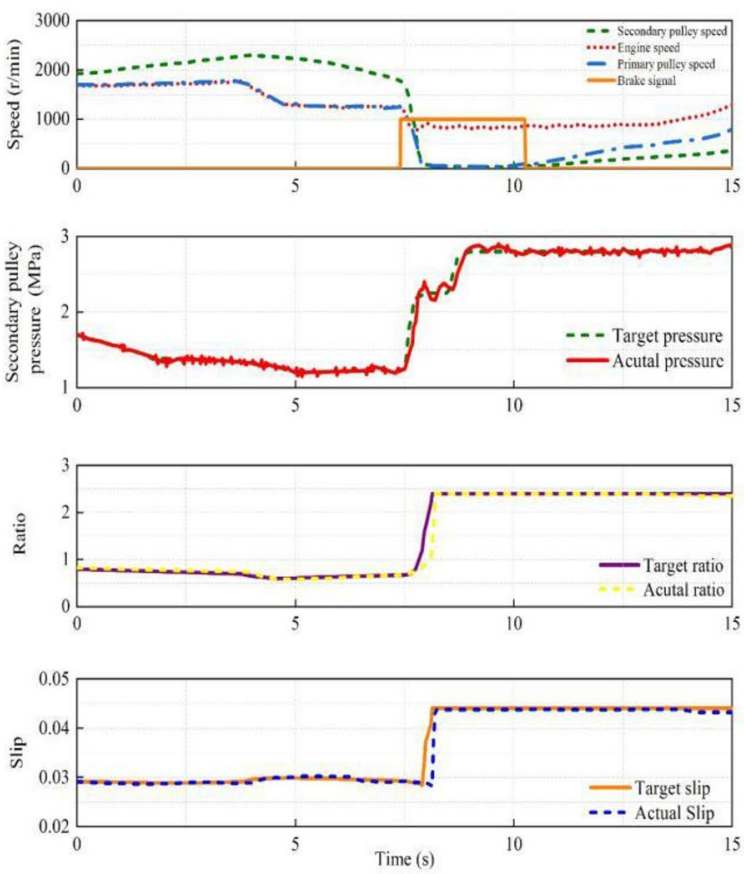

(b)
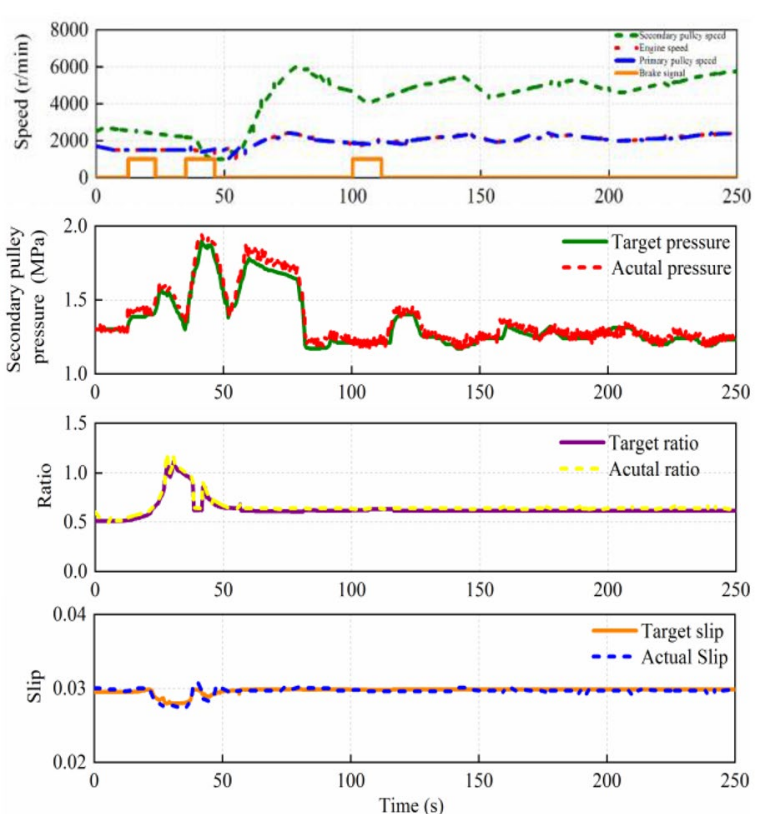

(c)

Figure $23 \mathbf{a}, \mathbf{b}$ and $\mathbf{c}$ are working condition test of CVT vehicle for the accelerate, the rapid deceleration and the comprehensive conditions respectively

performance testing. The test content includes the CVT pulley speed, slip, vehicle instantaneous fuel consumption rate, ratio, secondary pulley pressure and engine torque, the test results are shown in Figure 20. The NEDC cycle is composed of urban areas, suburbs and highways. The total test time is $18000 \mathrm{~s}$, of which the urban areas cycle test period is $0-6000 \mathrm{~s}$, suburbs cycle test period is $6000-12000 \mathrm{~s}$ and the remaining time period is the 
highway cycle test. Figure 20a and $\mathrm{f}$ show the CVT primary and secondary pulley speed and engine torque under NEDC cycle conditions at different times. Changes in speed and engine torque are observed. Figure $20 \mathrm{~b}$ is the slip, where the actual slip can better track the target slip during the test and meet the vehicle control requirements. Figure 20c shows the instantaneous vehicle fuel consumption rate. The fuel consumption corresponding to the controller based on the MPC is $7.26 \mathrm{~L} / 100 \mathrm{~km}$, which decreases by approximately $5.4 \%$ compared with the traditional safety factor. Figure 20d shows the tracking state of the actual CVT ratio to the target ratio under the NEDC cycle. Although the actual ratio is greater than the target ratio in several time periods, their difference is not large. In general, the CVT actual ratio optimised by the designed controller can track the target well and meet the control needs of the vehicle. Figure 20e compares the CVT secondary pulley pressure based on MPC and safety factor control strategies. Analysis of the results shows that compared with the traditional safety factor control strategy, the secondary pulley pressure optimised by the MPC clamping force controller obtains better value than the safety factor control strategy. The controller can more accurately and reasonably optimise the CVT clamping force.

To verify the control effect of MPC, the MPC control strategy and the traditional control strategy are simulated and compared. The test content includes the simulation test of the secondary cylinder pressure in the comprehensive working condition, acceleration condition and braking condition. Figure 21 shows the comparison results of the pressure of the secondary cylinder under comprehensive working conditions. The average pressure of the secondary cylinder of the MPC control strategy and the traditional control strategy are about $1.9 \mathrm{MPa}$ and $2.1 \mathrm{MPa}$, respectively. When the pressure of the secondary cylinder changes rapidly, the control effect of the MPC optimization strategy is still better than the traditional control strategy. Therefore, the MPC control strategy has more excellent control effects.

When the speed of the drive motor of the gantry is $3000 \mathrm{r} / \mathrm{min}$, the speed ratio is 1.2 , and the torque reaches $110-120 \mathrm{~N} \cdot \mathrm{m}$, the transmission efficiency reaches the peak value and tends to be stable. Compared with the traditional control strategy, the transmission efficiency of the system using the MPC control strategy can be increased by about $9.12 \%-9.35 \%$, as shown in Figure 22.

\section{Drum Test}

The control effect is verified using a full-vehicle drum test under comprehensive conditions. The designed controller is transplanted to the real vehicle for verification and the calibration tool CANape is used to collect and record the data. The test platform uses an independent Chinese brand of automotive CVT, the test parameters in Tables 2 and 3 , respectively.

Figure 23 shows the response changes of CVT vehicle under the accelerate, the rapid deceleration and the

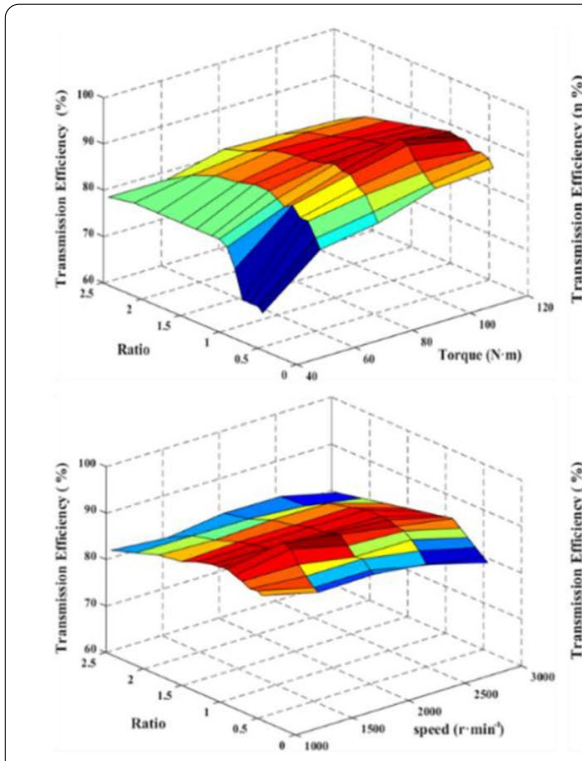

(a)
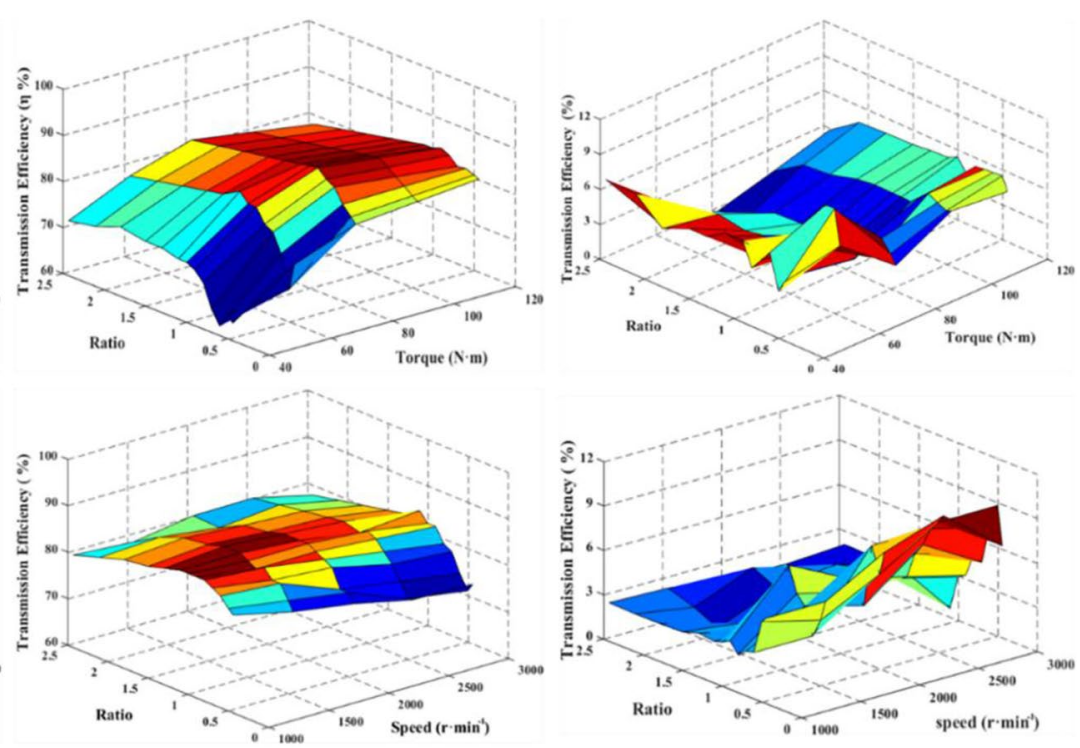

(b)

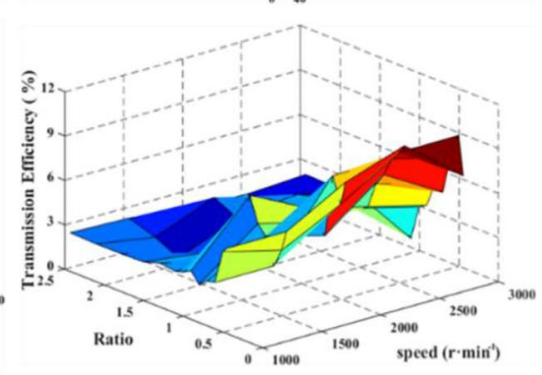

(c)

Figure 24 Comparison of efficiency improvement of CVT: a Traditional control, b MPC control, c efficiency difference 
comprehensive conditions. The improved speed ratio and pressure tracking of the control software meets the vehicle operation requirements, and the clamping force is considerably reduced under the action of the slip rate controller.

Therefore, the control software works well in real vehicles. The engine speed ranges within 1000-3000 r/min, ratio ranges within $0.44-2.432$ and torque ranges within 40-120 N.m. Figure 24 shows the transmission efficiency improvement of CVT test results based on MPC control and traditional safety factor control. The threedimensional maps show that when the engine torque and speed increase, the efficiency of the CVT transmission also increases. Compared with traditional safety factor, the efficiency of CVT vehicle based on MPC improves by approximately $9.12 \%-9.35 \%$.

\section{Conclusions}

This study proposes a new integrated optimization control method to meet the CVT expected transmission efficiency range, which conventional control cannot achieve. A new slip state dynamic equation is obtained and the clamping force bench is established. The relationship between the driver intention and the target ratio is obtained to control the actual ratio in real time. Then, a comprehensive optimization control strategy based on engine and transmission is proposed based on driver intention and slip. Finally, the controller is transplanted to the domestic CVT vehicle on the turntable to determine the efficiency under comprehensive working conditions. The main findings can be summarised as follows.

(1) The slip characteristics and related constraints are considered and new slip dynamics mathematical model and the clamping force test bench are established. The working characteristics of the engine determine economic working curve of the vehicle.

(2) The input variable accelerator pedal opening and its rate of change are analysed and processed based on fuzzy control strategy to obtain the relationship between the driver intention and the CVT target ratio at the corresponding time.

(3) Firstly, the internal combustion engine torque and slip between the metal belt and pulley are taken as optimization targets. Then, a joint controller based on MPC is designed, which allows the controller to repeatedly solve the optimization in real-time.

(4) The new and tested controller has good robustness and the vehicle performance under NEDC comprehensive condition is verified. Compared with traditional control, the new control method can improve efficiency by approximately $9.12 \%-9.35 \%$.

\section{Acknowledgements}

Not applicable.

\section{Authors' Contributions}

$\mathrm{LH}$ was in charge of the whole trial; $\mathrm{HL}$ wrote the manuscript; $\mathrm{HZ}$ and RF assisted with sampling and laboratory analyses. All authors read and approved the final manuscript.

\section{Authors' Information}

Ling Han, born in 1984, is currently an associate professor at Changchun University of Technology, China. She received her PhD degree from Jilin University, China, in 2015. Her research interests include mechatronics engineering, machine transmission system.

Hui Zhang, born in 1995, is currently a master at Changchun University of Technology, China. He received his master degree on mechatronics from Changchun University of Technology, China, in 2018.

Ruoyu Fang, born in 1995, is currently a master at Changchun University of Technology, China. He received his master degree on mechatronics from Jilin University, China, in 2018

Hongxiang Liu born in 1995, is currently a master at Changchun University of Technology, China. He received his master degree on mechatronics from Changchun University of Technology, China, in 2019.

\section{Funding}

Supported by National Natural Science Foundation of China (Grant No. 51905044), Postdoctoral Science Foundation of China (Grant No. 2017M611316).

\section{Availability of Data and Materials}

The datasets supporting the conclusions of this article are included within the article.

\section{Competing Interests}

The authors declare no competing financial interests.

\section{Author Details}

${ }^{1}$ School of Mechanical and Aerospace Engineering, Jilin University, Changchun 130025, China. ${ }^{2}$ School of Mechatronic Engineering, Changchun University of Technology, Changchun 130012, China.

Received: 19 November 2020 Revised: 1 September 2021 Accepted: 26 September 2021

Published online: 06 November 2021

\section{References}

[1] X H Zeng, Z Q Wu, Y Wang, et al. Multi-mode energy management strategy for hydraulic hub-motor auxiliary system based on improved global optimization algorithm. Sci. China Tech. Sci., 2020, 63(10). https:// doi.org/10.1007/s11431-019-1526-8.

[2] K Hudha, M L H A Rahman, N H Amer, et al. Ratio tracking control of slider crank based electromechanical CVT system. 2018 57th Annual Conference of the Society of Instrument and Control Engineers of Japan (SICE), 2018: 1530-1537, doi: https://doi.org/10.23919/SICE.2018.84925 96

[3] ASciarretta, G de Nunzio, L L Ojeda. Optimal ecodriving control: energy-efficient driving of road vehicles as an optimal control problem. IEEE Control Syst., 2015, 35: 71-90.

[4] Eiji Tsuchiya, Eiji Shamoto. Formulation of intervibrator motion and development of a controller for a pulse-drive transmission. Mechanism and Machine Theory, 2020, 150: 103880.

[5] Chih-Hong Lin. Novel application of continuously variable transmission system using composite recurrent Laguerre orthogonal polynomials modified PSO NN control system. ISA Transactions, 2016, 64: 405-417.

[6] H B Khaniki, H Zohoor, S Sohrabpour. Performance analysis and geometry optimization of metal belt -based continuously variable transmission systems using multi-objective particle swarm optimization. Journal of the Brazilian Society of Mechanical Sciences \& Engineering, 2017, 39(3): 1-15 
[7] Hongxiang Liu, Ling Han, Yue Cao. Improving transmission efficiency and reducing energy consumption with automotive continuously variable transmission: A model prediction comprehensive optimization approach, Applied Energy, 2020, 274:115303.

[8] Daohai Qu, Wei Luo, Yunfeng Liu, et al. Simulation and experimental study on the pump efficiency improvement of continuously variable transmission. Mechanism and Machine Theory, 2019, 131: 137-151.

[9] Xiang Ren, Dawei Li, Ronghai Qu, et al. Back EMF harmonic analysis of permanent magnet magnetic geared machine. IEEE Transactions on Industrial Electronics, 2020, 67(8): 6248-6258.

[10] N Hayashi, A Sugiura, Y Abe, et al. Development of ignition technology for dilute combustion engines. SAE International Journal of Engines, 2017, 10: no. 2017-01-0676.

[11] G Z He, H Xie, S J He. Overall efficiency optimization of controllable mechanical turbo-compounding system for heavy duty diesel engines. Sci. China Tech. Sci., 2017, 60: 36-50, doi: https://doi.org/10.1007/ s11431-015-0754-6.

[12] F X Liu, W Wu, J B Hu, et al. Design of multi-range hydro-mechanical transmission using modular method. Mechanical Systems and Signal Processing, 2019, 126: 1-20.

[13] K Harima, S Tsuchiya, T Morino, et al. Internal thrust force analysis of CVT push belt. SAE Technical Paper, 2016: 2016-01-2353.

[14] B Bonsen, T Klaamssen, K Meerakker, et al. Analysis of slip in a continuously variable transmission. American Society of Mechanical Engineers: International Mechanical Engineering Congress and Exposition, Dynamic Systems and Control, November 15-21, 2003, Washington DC, USA, 2003: 995-1000.

[15] Yulong Lei, Yuzhe Jia, Yan Fu, et al. Car fuel economy simulation forecast method based on CVT efciencies measured from bench test. Chin. J. Mech. Eng., 2018, 31:83.

[16] M L H Abd Rahman, K Hudha, Z A Kadir, et al. Modeling and validation of a novel continuously variable transmission using slider crank mechanism. International Journal of Engineering Systems Modelling and Simulation (IJESMS), 2018, 10(1): 49-61.

[17] S Akehurst, N D Vaughan, D A Parker, et al. Modeling of loss mechanisms in a pushing metal v-belt continuously variable transmission. Part 2: Deflection losses and total torque loss validation. Proc IMechE Part D: Journal of Automobile Engineering, 2004, 218(11): 1295-1306.

[18] X Tang, T Jia, X Hu, et al. Naturalistic data-driven predictive energy management for plug-in hybrid electric vehicles. IEEE Transactions on Transportation Electrification, 2021, 7(2): 497-508, doi: https://doi.org/ 10.1109/TTE.2020.3025352.

[19] J Ruan, P Walker, N Zhang. A comparative study energy consumption and costs of battery electric vehicle transmissions. Appl. Energy, 2016, 165: 119-134.
[20] A Olyaei. Novel continuously variable transmission mechanism. SN Appl. Sci., 2019, 1: 1032. https://doi.org/https://doi.org/10.1007/ s42452-019-1081-4Antti.

[21] Ritari, Jari Vepsäläinen, Klaus Kivekäs, et al. Energy consumption and lifecycle cost analysis of electric city buses with multispeed gearboxes. Energies, 2020, 13: 2117.

[22] D F Pick, D-Y D Wang, R W Proctor, et al. Dead pedal and the perception of performance of a continuously variable transmission. Proceedings of SAE 2005 World Congress and Exhibition, Detroit: SAE, 2005.

[23] J H Zhao, S T Zhou, Y F Hu, et al. Open-source dataset for controloriented modelling in diesel engines. Sci. China Inf. Sci., 2019, 62(7): 077201, https://doi.org/https://doi.org/10.1007/s11432-018-9783-x.

[24] S Kim, J Sim, J Park, et al. Elastomeric continuously variable transmission combined with twisted string actuator. IEEE Robotics and Automation Letters, 2020, 5(4): 5477-5484.

[25] K J Qin, E H Wang, H Zhao, et al. Development and experimental validation of a novel hybrid powertrain with dual planetary gear sets for transit bus applications. Sci. China Tech. Sci., 2015, 58: 2085-2096.

[26] L J Qian, L H Qiu, P Chen, et al. Fuel efficient model predictive control strategies for a group of connected vehicles in corporating modelbased adaptive control system for stable steering of distributed driver electric vehicle under various road excitations. ISA Transactions, 2020, 103: 37-51.

[27] María F Villa-Tamayob, Michelle A Caicedob, Pablo S Rivadeneiraa. Offset-free MPC strategy for nonzero regulation of linear impulsive systems. ISA Transactions, 2020, 101: 91-101.

[28] M Korda, I Mezić. Linear predictors for nonlinear dynamical systems: Koopman operator meets model predictive control. Automatica, 2018, 93: 149-160.

[29] Jiangyan Zhang, Tielong Shen. Real-time fuel economy optimization with nonlinear MPC for PHEVs. IEEE Trans. Control Syst. Tech., 2016, 24: 1-9.

[30] Ke Shi, Dong Cheng, Xiaofang Yuan, et al. Interacting multiple modelbased adaptive control system for stable steering of distributed driver electric vehicle under various road excitations. ISA Transactions, 2020, 103: 37-51.

[31] L Guo, B Gao, Y Li, et al. A fast algorithm for nonlinear model predictive control applied to HEV energy management systems. Sci. China Inf. Sci., 2017, 60: 092201.

[32] S Beuerle. Optimization methodology for CVT ratio scheduling with consideration of both engine and CVT efficiency. USA: Western Michigan University, 2016.

\section{Submit your manuscript to a SpringerOpen ${ }^{\circ}$ journal and benefit from:}

- Convenient online submission

- Rigorous peer review

- Open access: articles freely available online

- High visibility within the field

Retaining the copyright to your article

Submit your next manuscript at springeropen.com 